\title{
Core pathways controlling shoot meristem maintenance
}

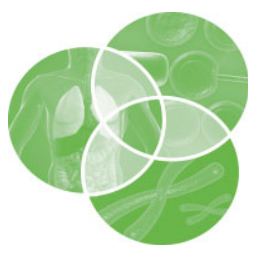

\author{
Chunghee Lee and Steven E. Clark*
}

Essential to the function of shoot meristems in plants to act as sites of continuous organ and tissue formation is the ability of cells within the meristem to remain undifferentiated and proliferate indefinitely. These are characteristics of the stem cells within meristems that are critical for their growth properties. Stem cells are found in tight association with the stem cell niche-those cells that signal to maintain stem cells. Shoot meristems are unique among stem cell systems in that the stem cell niche is a constantly changing population of recent daughter stem cells. Recent progress from Arabidopsis and other systems have uncovered a large number of genes with defined roles in meristem structure and maintenance. This review will focus on well-studied pathways that represent signaling between the stem cells and the niche, that prevent ectopic differentiation of stem cells, that regulate the chromatin status of stem cell factors, and that reveal intersection of hormone signaling and meristem maintenance. ๑ 2013 Wiley Periodicals, Inc.

How to cite this article:

WIREs Dev Biol 2013, 2:671-684. doi: 10.1002/wdev.110

\section{INTRODUCTION}

S ince shoot apices were first observed in 1759 , the shoot meristem has become the major focus of plant biology research. Investigations have focused on the diversity, morphology, histology, cell divisions, and cell lineages of the shoot meristem. ${ }^{1-4}$ A critical aspect of meristem function is the stem cell-like activity of a subset of cells of the meristem. Specifically, meristematic cells require a delicate balance of self-renewal and differentiation. This homeostatic characteristic is essential for the meristem to act as a site of continuous organogenesis. Our understanding of the regulatory control of meristem development advanced rapidly with the advent of Arabidopsis molecular genetic studies. During this period, a large array of genes and mutants have been identified that effect meristem development. ${ }^{5}$ A number of these genes function in well-studied pathways that are critical for meristem homeostasis and are the focus of this review.

The Arabidopsis shoot meristem is one of a number of indeterminate sites of organogenesis and continuous growth (others include the flower,

*Correspondence to: clarks@umich.edu

Department of Molecular, Cellular and Developmental Biology, University of Michigan, Ann Arbor, MI, USA root, and vascular meristems $\left.{ }^{4,6}\right)$. The shoot meristem specifically is the ultimate source of all organs above the ground: stems, leaves, and flowers. During the globular stage of embryogenesis, the precursors of the shoot apical meristem are established. By heart stage of embryogenesis, both the cotyledon primordia and the early shoot meristem have been established. ${ }^{7-10}$ Postembryonically, lateral shoot meristems repeatedly arise from the axils of leaves to form secondary and high-ordered shoots. ${ }^{6,11,12}$ In addition, various Arabidopsis mutants that lack shoot meristems will undergo a poorly understood process of adventitious meristem initiation. ${ }^{13,14}$ Once formed, indeterminate shoot meristems must be maintained through a process of homeostasis that can act over a period of weeks or decades, depending on the plant species. While not the focus of this review, the homeostatic controls must be highly sensitive to environmental and physiological conditions and adapt to changing rates of growth as well as periods of quiescence.

The shoot meristem contains a population of undifferentiated self-renewing cells at the central apex (Figure 1). These stem cells are the source of new organs and tissues for the plant. Peripheral and basal daughter cells (see below) move toward differentiation, divide much more rapidly, and organize into distinct organ primordia (Figure $1 \mathrm{~b}$ ). 
(a)
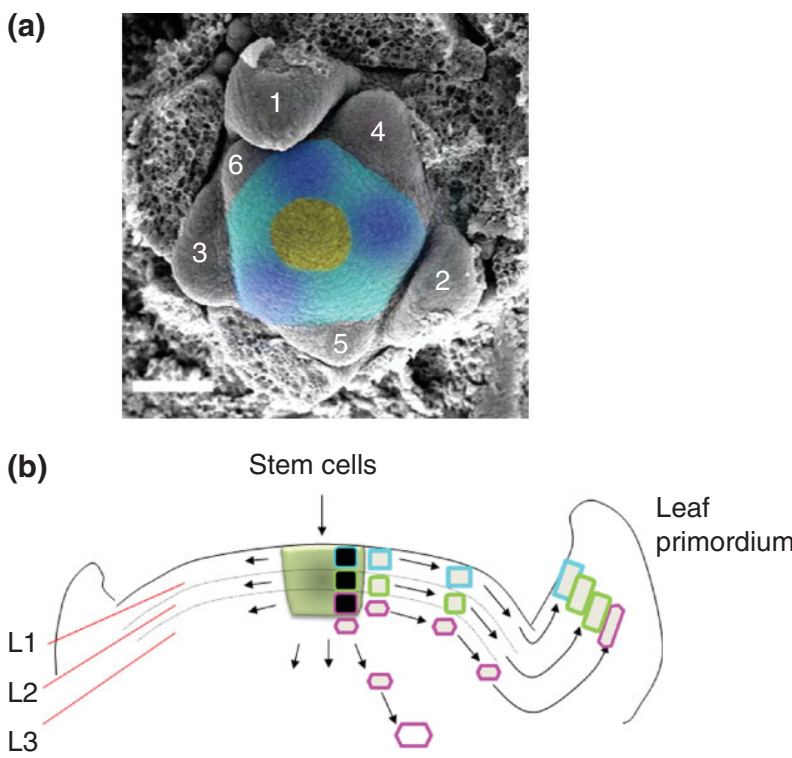

FIG URE 1 | The shoot meristem. (a) A scanning electron micrograph of an Arabidopsis shoot apical meristem. Recently formed organ primordia are numbered from oldest to youngest. The $\mathrm{CZ}$ region, $\mathrm{PZ}$ region, and sites of nascent organ primordia are false-colored yellow, blue, and dark blue, respectively. (b) Diagrammatic cross section of a shoot meristem. The L1, L2, and L3 layers of cells in the meristem center are indicated. The region of stem cells is indicated, and individual stem cells are shown (black cells) along with their predicted cell fates. Arrows indicate the fate of cells over developmental time, not the movement of cells.

The central and peripheral regions of the meristem were initially identified based on their histological characteristics. The more slowly dividing central stem cells were termed the central zone (CZ), while the more rapidly dividing and cytoplamsically dense peripheral cells were termed the peripheral zone (PZ). ${ }^{4}$ While technically a description of cell morphology, CZ and $\mathrm{PZ}$ are used as shorthand for the central stem cells and their peripheral differentiating daughter cells, respectively. $3,5,6,11,15-17$

In addition to this zonal division, the shoot meristem is organized into distinct cell layers (Figure 1b). In Arabidopsis, the outermost L1 and L2 layers (the tunica) are normally maintained as clonally distinct because cell divisions in these layers are strictly anticlinal in the meristem center. The more internal L3 layer, on the other hand, divides both anticlinally and periclinally. ${ }^{18-21}$

The stem cell population must be maintained while appropriately positioned peripheral and basal daughter cells are directed toward organ primordia and other differentiated tissues. The maintenance of these stem cells is influenced by their position, or niche. At the shoot meristem, the niche is driven by an Organizing Center (OC), which is located at the base of the CZ of the shoot meristem. ${ }^{14,22,23}$ Critically, the OC is a constantly changing population of cells (see below). Because the L1, L2, and L3 layers are clonally distinct, each needs to maintain a population of stem cells in the very center during the process of cell division. In the L1 and L2 layers, it is the centrally located daughter cell that remains a stem cell, while the peripheral daughter cell makes a transition toward differentiation. Within the L3 layer, cells that undergo periclinal divisions require the apical daughter cell to retain stem cell identity, while the basal daughter cells differentiate. ${ }^{18-21}$

The balance between stem cell specification and differentiation is also involved in flower meristem function. Floral primordia are initiated on the flanks of the shoot meristem and a floral meristem is established. The floral meristem is a modified shoot meristem and thus also requires a process of stem cell maintenance; however, within the floral meristem, stem cells are transiently maintained. . $^{2,24}$ Stem cell maintenance at the shoot and flower meristems can vary considerably between different plant species. ${ }^{4}$

\section{THE WUS-CLV PATHWAY}

A large number of factors influence and control shoot meristem maintenance. Rather than covering every gene with an effect on meristem development, this review will focus on the best-characterized pathways. The meristem homeostasis pathway explored in greatest detail is the WUS-CLV pathway. The essential nature of this pathway is exemplified by the mutant phenotypes from disruption of this pathway that range from shoots with no stem cells to shoots with only stem cells. ${ }^{14,25-28}$ This pathway appears to be central for signaling between the stem cells and the underlying OC.

WUS is a transcription factor and the founding member of the WOX homeodomain family found throughout plants. ${ }^{14}$ WUS expression is initiated at the 16-cell stage of embryogenesis and becomes progressively restricted to the basal daughter cells of the L3 stem cells as the embryonic shoot meristem is formed. ${ }^{22}$ In the active shoot meristem, the expression domain of WUS defines the OC which acts as the stem cell niche. ${ }^{14,22}$ The earliest studies on WUS observed: (1) wus mutants fail to establish or maintain stem cells at shoot meristems (wus mutants reiteratively form adventitious shoots which also fail to maintaining stem cells); (2) WUS is expressed in the OC; (3) WUS overexpression within the meristem drives ectopic stem cell accumulation. ${ }^{14,22,23}$ The long-held model that evolved from this data was that WUS acts to 


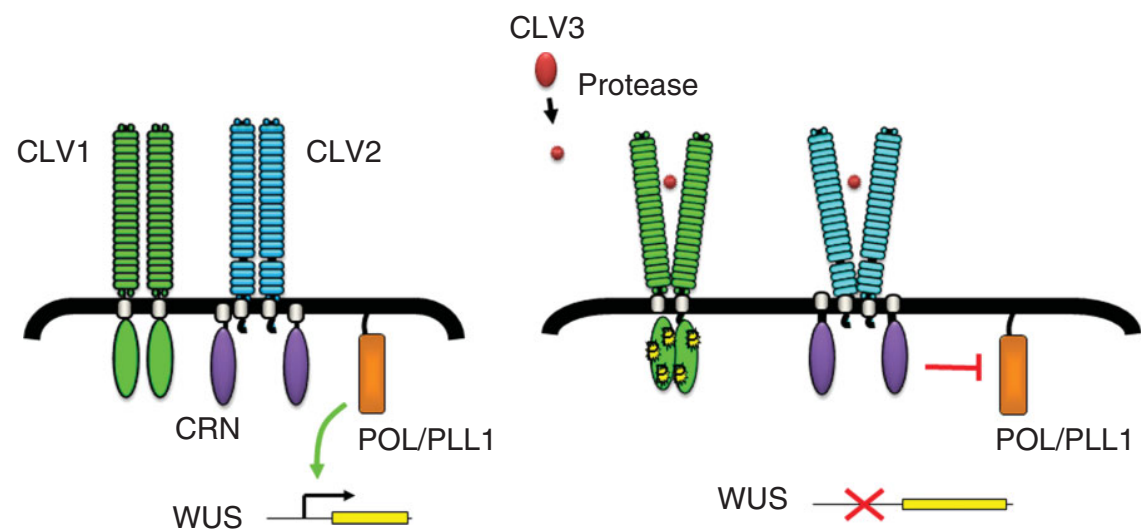

FI G URE 2 | A model for CLAVATA (CLV) signaling. In the absence of CLV3 ligand, CLV1 and CLV2/CRN complexes are inactive, allowing POL/PLL1 to (likely indirectly) promote WUS transcription. Mature and processed CLV3 activates the receptor complexes, repressing POL/PLL1. In the absence of POL/PLL1 activity, WUS transcription is not maintained. The CLV1-redundant BAM receptors are not included for clarity.

specify the OC, which in turn signals to the overlying cells to maintain stem cell identity.

A potentially enlightening twist to this model was recently proposed based on data on the movement of WUS protein within the meristem. Reddy and colleagues observed movement of a GFP-tagged WUS protein into the stem cell layers of wild-type shoot meristems, presumably through the plasmodesmata. ${ }^{29}$ Nuclear-targeted or double-GFP tagged WUS protein had restricted movement and failed to completely rescue wus mutant plants, providing a correlation between movement and WUS function. While these experiments are not definitive as of yet, they open up a completely novel way of looking at the nature of stem cell/niche interactions.

One aspect of WUS transcriptional regulation has been extensively studied, that is the limitations of WUS expression by the CLAVATA (CLV) signaling pathway (Figure 2). clavata (clv) mutants have opposite phenotypes to wus mutant in that clv mutants have enlarged meristems, specifically accumulating stem cells. ${ }^{25-27}$ Evidence suggests this is the result of WUS expression expanding into the L3 layer of stem cells in $\mathrm{clv}$ mutants so that WUS is expressed in both the apical and basal L3 daughter cells. The interpretation of these $c l v$ phenotypes is that the expanded OC represented by WUS expression leads to ectopic stem cell specification on the overlying cell layers. ${ }^{23,30}$

The CLV pathway is composed of a numbers of factors. These include the receptor-kinases CLV1, BAM1, and BAM2, the receptor-like protein CLV2, the transmembrane kinase-related protein (but, catalytically inactive) CRN, the secreted ligand CLV3 and the membrane-associated protein phosphatases POL and PLL1. $31-38$

CLV signaling starts with CLV3, which is specifically expressed in what appears to be the stem cells of the shoot meristem ${ }^{33,39}$ (Figure 2). CLV3 is a founding member of the CLE family of secreted peptides found throughout land plants. ${ }^{40-42}$ CLV3 undergoes extracellular proteolytic maturation to release the short CLE peptide (likely 12 or 13 amino acids) from the precursor protein. ${ }^{43-47}$ CLV3 may undergo further maturation through hydroxyproline modification and arabinosylation. ${ }^{44,47}$ Because the active CLV3 signal is a small peptide, no direct monitoring of CLV3 diffusion has been possible, but indirect evidence suggests it moves quite broadly throughout the meristem. ${ }^{48-50}$ The mature CLV3 peptide binds to a number of plasma membrane receptors, the most important (based on mutant phenotypes) being CLV1 and CLV2. Interestingly, CLV3 binds to both these receptors at similar affinities, and both binding events appear to be essential for CLV signaling. ${ }^{51-53}$ Mature CLV3 also binds to the CLV1-redundant receptors BAM1 and BAM2, ${ }^{52}$ and a potential parallel pathway involving the related receptor RPK2. ${ }^{54}$ How CLV3 binding effects receptor activation and what activation means in terms of receptor function are unclear. Genetic analysis demonstrates that CLV3 acts upstream as a positive regulator of CLV1 and CLV2, thus CLV3 binding to these receptors presumably activates their ability to signal within the cell. Evidence from Arabidopsis shoot meristems supports the presence of two receptor complexes: CLV1/BAM multimers and CLV2/CRN heteromultimers $^{52}$ (Figure 2). Higher order receptor complexes have been detected in transient expression only. ${ }^{51,52,55}$ How these receptors signal within the cell is unclear; indeed, the CLV2/CRN complex lacks a catalytically active cytoplasmic signaling domain. ${ }^{36}$ In other receptor systems, internalization can be linked to signaling, receptor recycling, and feedback inhibition.

POLTERGEIST (POL) is a critical target of CLV signaling. Originally identified in a $c l v$ mutant 
suppressor screen, POL and the related PLL1 are signaling intermediates between the CLV receptors and WUS regulation. ${ }^{28}$ The pol pll1 double mutant is seedling lethal due to loss of asymmetric cell divisions in the early embryonic hypophyseal and procambial cells. ${ }^{56}$ However, grafting the apices of pol pll1 seedling to wild-type roots revealed that the pol pll1 tissue phenocopied wus mutants and failed to maintain WUS expression in the shoot. Thus, POL/PLL1 promote WUS transcription and are repressed by CLV signaling ${ }^{28}$ (Figure 2). Interestingly, POL/PLL1 localize to the cytoplasmic face of the plasma membrane via dual acylation. ${ }^{57}$ In addition, POL/PLL1 bind to, and are catalytically activated by, phosphatidylinositol 4-phosphate in vitro. ${ }^{57}$ Considering that CLV1 endocytosis is triggered by CLV3 activation, there may be a link between receptor activation, phospholipids, and cytoplasmic signaling.

Even though WUS has been studied as a major factor regulating stem cell specification and maintenance, how WUS functions to specify stem cells is not known in detail. A useful resource of meristem gene expression profiling was published by Reddy and co-workers. ${ }^{58}$ In this study, cells of the meristem were sorted in one of three regions: the stem cell region (marked by CLV3), the OC (marked by WUS), or the periphery (marked by FIL). Each of the populations was then used for microarray analysis to provide a transcriptome profile for each region. This resource provides both a list of potential marker genes and effectors for the key aspects of meristem maintenance.

Other recent advances in identifying WUS transcription targets have been made. WUS has been shown to directly bind genes encoding ARR-A isoforms, which act in a negative feedback loop of cytokinin signaling. ${ }^{59}$ Comparative microarray using plants with ethanol-inducible overexpression WUS, STM, and LFY was performed and 148 candidate genes were identified to responsive in WUS overexpression but not STM and LFY. ${ }^{59}$ Four genes encoding ARR-A isoforms ( $A R R 5, A R R 6, A R R 7$, and $A R R 15)$ were among 148 genes. Quantitative RTPCR showed that the transcription level of ARR-A type genes is sensitively reduced by WUS induction. The results of chromatin immunoprecipitation (ChIP) and electrophoretic mobility-shift assays (EMSAs) indicated that WUS directly binds to the cis elements of ARR7. These results suggest a direct interaction between WUS/CLV signaling and cytokinin signaling for meristem formation and maintenance.

Busch and colleagues performed genomic and transcriptomic analysis to identify downstream targets of WUS using a suite of WUS loss-of-function and gain-of-function backgrounds. ${ }^{60}$ By this analysis, more than 100 potential direct transcriptional WUS target genes were identified. Thus, WUS could affect a large number of downstream genes to maintain stem cell integrity. Interestingly, CLV1, which negatively regulates WUS, was identified as one of the direct targets of WUS, suggesting WUS may bind to CLV1 and modulate its expression. Because WUS and CLV1 expression domains extensively overlap, ${ }^{22,31}$ this regulation would likely be one to modulate the levels, not region, of CLV1 transcription. One aspect of these genomic studies that requires further investigation is the observation that the targets identified as WUS protein-binding sites in the genome were largely independent of the genes identified as transcriptionally controlled by WUS activity.

A critical WUS target within the meristem is CLV3. This creates a feedback loop, whereby CLV signaling restricts WUS expression to the OC, while WUS induces CLV3 expression in the overlying stem cells. The evidence for WUS induction of CLV3 was based both on the loss of CLV3 expression in wus mutants and the ectopic expression of CLV3 driven by WUS overexpression. ${ }^{23,30}$ More recently a potentially direct mechanism for this induction has been proposed. In addition to providing evidence of WUS protein movement to the stem cells, Reddy et al. demonstrated that WUS binds to the region of CLV3 cis elements in EMSA experiments. ${ }^{29}$

In addition, WUS may have a direct or indirect role in controlling the rate of growth and proliferation in the PZ. Transiently induced WUS expression led to not only expansion of the stem cell region, but also an increased cell division rate in the PZ. Conversely, decreased WUS level result in smaller CZ and a reduction of cell division rate. ${ }^{61}$ Whether this reflects direct WUS control of the $\mathrm{PZ}$ or an underlying compensatory mechanism between $\mathrm{CZ}$ and $\mathrm{PZ}$ growth remains to be determined.

\section{PRE-DIVISION VERSUS POST-DIVISION MODEL FOR CLV/WUS CONTROL}

A variety of evidence suggests that the primary function of CLV signaling in shoot meristem homeostasis is to restrict WUS expression in the L3 stem cell layer. Two different models have been proposed for how this WUS repression is achieved. These models differ in the timing of CLV signaling relative to the division of the $\mathrm{L} 3$ stem cells.

One way to view L3 stem cell divisions is to see them as asymmetric. L3 cells undergoing periclinal (apical/basal) divisions have very different fates adopted by the two daughter cells. The apical daughter cell remains as a stem cell and continues 
WUS repression. The basal daughter cell activates WUS expression and becomes part of the stem cell niche OC (see above).

In $c l v$ mutants, a key aspect of asymmetry is lost, namely, the differential WUS expression. Whether other aspects of asymmetry between apical and basal L3 daughter cells are lost in $c l v$ mutants has not been ascertained. Thus, one way to view $c l v$ mutants is that they lose L3 cell asymmetry. This could result from a role for CLV signaling in maintaining cell asymmetry either after or before L3 cell division.

The postdivision model, developed from the earliest evidence of CLV repression of WUS, hypothesizes that active CLV signaling is required continuously to prevent WUS expression from being activated in the L3 stem cell layer (i.e., in the apical daughter cells of divided L3 stem cells). An interesting challenge for this model is that it requires functional CLV signaling in the L3 stem cell layer, but no CLV signaling one cell away in the OC. A possible mechanism for this differential signaling is ligand sequestration, where sufficient levels of the receptor deplete the ligand from apoplasm. Ligand sequestration essentially acts to dramatically increase the gradient of ligand concentration and has been observed in some animal signaling systems. Studies using CLV3 overexpressed specifically in the L1 layer interrupted the ability of CLV1 expression to block the effects of this ectopic CLV3 expression as evidence of ligand sequestration. ${ }^{48}$ However, a more recent study analyzing the internalization of CLV1 in response to activation by CLV3 reported no evidence of ligand sequestration. ${ }^{49}$ The challenge for definitively establishing whether CLV1/CLV2/BAM receptors can limit the range of CLV3 diffusion is that there is currently no way to detect the active form of CLV3 within the meristem. This is because CLV3 is proteolytically processed with additional hydroxyproline and arabinosylation modifications (see above). Which form of mature CLV3 is produced and physiologically active within the shoot meristem is unknown. A further challenge for the model is that the L3 cells themselves express CLV3, at least at the transcriptional level. ${ }^{33}$ This CLV3 expression, if converted into active CLV3 ligand, would not activate CLV signaling in the immediately adjacent basal daughter cell.

A second model postulates that CLV signaling acts prior to division of the L3 stem cell. In this scenario, CLV signaling acts to polarize the L3 stem cell prior to division, with the differential fates, and corresponding differential WUS expression, being driven by cell asymmetry established earlier. ${ }^{56}$ Here, CLV3 would act as a cell polarity signal to drive an apical domain with the L3 stem cells. In the absence of this signal, L3 stem cells fail to adopt an apical cell fate after division, leading to basal fate and WUS expression in both the daughter cells. This model is inspired by the embryonic phenotypes of mutations in the CLV signaling intermediates POL and PLL1 (see above). During embryonic development, pol pll1 double mutants lose asymmetric character to both the hypophyseal and procambial cells. ${ }^{56}$ One advantage of this model is that CLV3 expression from the L3 cells would not disrupt polarity establishment as long as there is an apical-basal gradient of CLV3 across the L3 stem cell. One drawback is that there are currently no studies assessing whether L3 cells and their basal daughter cells have lost other aspects of cell asymmetry (potentially cell morphology, cell division rates, markers for OC identity) in $c l v$ mutants.

One critical feature that we must keep in mind when thinking about the mechanism of the CLV/WUS system in regulating stem cell homeostasis is that these signaling events take place over days. The cell cycle time of cells within the shoot meristem of Arabidopsis is on the order of $18-72 \mathrm{~h}$, depending on where the cell is located. CZ cells have a cell cycle length of $1.5-3$ days, ${ }^{62}$ thus CLV signaling is a long-term maintenance program that may not act like other signaling events where the introduction of ligand leads to rapid changes in cell identity. L3 stem cells presumably are always detecting CLV3 ligand. Indeed, in studies on altering CLV3 activity within the meristem no changes are seen prior to many hours after induction. ${ }^{39,63}$

\section{THE STM PATHWAY}

A separate regulatory pathway that appears to function in parallel with the WUS-CLV3 pathway to regulate shoot meristem maintenance includes the critical meristem regulator SHOOTMERISTEMLESS (STM). ${ }^{13,64-67}$ STM is a KNOX-class homeodomain transcription factor orthologous to the maize KNOTTED1 protein. ${ }^{68}$ The repression of stem cell differentiation by STM occurs by preventing the expression of the organ-formation factors ASYMMETRIC LEAVES1 (AS1) and AS2 in the center of the shoot meristem. ${ }^{69,70} A S 1$ is orthologous to PHAN Antirrhinum and ROUGH SHEATH2 $(R S 2)$ from maize. ${ }^{69}$ AS1 is a MYB domain transcription factor, while AS2 encodes a protein that contains an AS2/LATERAL ORGAN BOUNDARY (LOB) domain. ${ }^{69,71}$ In each species, these genes are involved in lateral organ initiation. While STM and related KNOX proteins (KNAT1/BP, KNAT2, and KNAT6) prevent ectopic AS1/AS2 activation 
in the center of the meristem, AS1/AS2 in turn repress the KNOX genes in developing organ primordia. ${ }^{69,70,72-74}$ The expression of STM typifies this regulation, with high expression throughout the center region of the meristem, but clearly downregulated in nascent organ primordia. ${ }^{69}$ The homologous and partially redundant KNAT genes are similarly downregulated in organ primordial but exhibit complex and different expression patterns within the meristem. ${ }^{69,70,72-75}$ Evidence suggests that the AS1/AS2 repression of KNOX transcription occurs by the ability of these interacting proteins to form a transcriptional repression complex on the $K N O X$ gene $c i s$ elements through interaction with the histone chaperone HIRA. 5,76

The STM pathway may also involve regulation of Gibberellin (GA) signaling. GAs comprise a large family of diterpenoid molecules that are involved in promoting organ expansion and morphogenesis in higher plants. ${ }^{77}$ The repression of GA activity by KNOX transcription factors in the $\mathrm{CZ}$ is important to maintain meristem integrity while upregulation of $\mathrm{GA}$ in the PZ contributes the generation of lateral organ development. ${ }^{5,17,78}$ Evidence for this comes from the Nicotiana tabacum homeobox 15 (NTH15) KNOX homeodomain protein, which represses the GA biosynthesis by directly binding the first intron of GA 20-oxidase (Ntc12) to maintain the indeterminate state. ${ }^{5,17,79} \mathrm{GA}$ 20-oxidase is key enzyme in GA biosynthesis. In Arabidopsis, exogenous GA application suppresses phenotypes from KNOX mis-expression, such as highly lobed leaves. ${ }^{79}$ Conversely, in Arabidopsis KNOX misexpression suppresses GA 20-oxidase expression in the leaves. ${ }^{80}$ In addition, the expression pattern of AtGA20ox1:GUS is complementary to STM expression. ${ }^{5,17,80}$

\section{miRNAs IN THE MERISTEM}

Shoot meristem maintenance is also affected by miRNAs. Evidence for a role in meristem development for a specific miRNA class, the factors involved in miRNA function, and the miRNA targets have emerged over the course of many studies.

A role for miRNAs in meristem maintenance came from the investigation of the miRNAs miR165 and miR166. ${ }^{81-85}$ Critically, the jabba-1D mutation, caused by constitutive overexpression of one of the genes encoding miR166, leads to defects in meristem maintenance, displaying enlarged shoot and floral meristem. ${ }^{85}$ miR166 along with the very similar miR165 target the set of five transcription factors in Arabidopsis that make up the class III homeodomain-leucine zipper transcription factors (HD-zip IIIs). ${ }^{81,83,84,86}$ jabba-1D mutants display enlarged shoot meristems, radialized leaves, and defective vasculature. Furthermore, WUS expression in jabba-1D is variable but expanded and WUS transcription levels are approximately 12 -fold higher in jabba-1D compared to wild-type. ${ }^{85}$

The HD-zip III transcription factors that are targeted by miR165/166 control critical aspects of meristem development. The HD-ZIP III family in Arabidopsis is composed of five members: REV, PHB, PHV, CNA, and ATHB8. ${ }^{87,88}$ HD-zip III genes had been previously characterized through both loss-of-function and gain-of-function mutations with effects on meristem development as well as many other aspects of plant development. ${ }^{89-94}$ The gain-offunction alleles are the result of silent substitutions leading to resistance to $m i R 165 / 166$ repression. ${ }^{90,91}$ Understanding the function of these genes is complicated by their simultaneously redundant and antagonistic roles. ${ }^{93}$ In establishing the embryonic shoot meristem, REV, PHB, PHV, and CNA all appear to work in parallel. However, in shoot and flower meristem development, REV works antagonistically to PHB, PHV, and CNA. Specifically, rev mutants lack or develop reduced meristems, while $p h b$ phv cna triple mutants exhibit enlarged meristems very similar to the $c l v$ mutants. ${ }^{92,93}$ The effect of the jabba-1D mutation is similarly antagonistic: $R E V$ transcripts increase in the jabba-1D mutants, while PHB/PHV/CNA transcripts decrease. ${ }^{85}$ Both these changes would be consistent with an enlarged shoot meristem.

In addition to the direct evidence from miR165/ 166 genetics, factors involved in miRNA processing and function also show evidence of roles in meristem regulation. Specifically, members of the ARGONAUTE (AGO) family show evidence of meristem function. The AGO family acts as central components of RNA-induced silencing complexes (RISC). ${ }^{95,96}$ AGOs contain a variable $\mathrm{N}$-terminal domain followed by conserved PAZ, MID, and PIWI domains. The PAZ and MID domain bind $3^{\prime}$ and $5^{\prime}$ ends of small RNAs, respectively, while the PIWI domain has a RNase $\mathrm{H}$ catalytic activity that allows the AGO/miRNA complex to cleave target mRNAs. ${ }^{95-97}$

Among 10 AGO members in Arabidopsis, ARGONAUTE1 (AGO1) and AGO10 (also known as ZWILLE or PINHEAD) have been shown to regulate shoot meristem development. ${ }^{98-103}$ AGO1 is required for stem cell function. A portion of ago1 mutants do not develop embryonic shoot meristem seedlings. ${ }^{99}$ However, postembryonic shoot meristems 
of ago1 mutants are larger than that of wild type. ago1 mutants fail to form axillary meristems and most of the mutant plants die within 6 weeks after germination. ${ }^{98,99}$ AGO1 has been shown to be required for STM expression, which has important role in meristem establishment and maintenance. ${ }^{101}$ These variable and conflicting effects on meristem development in the ago1 mutant may reflect the effect on ago1 on the function of multiple miRNAs. AGO10 similarly has differential roles for in embryonic shoot meristem initiation compared to postembryonic meristem maintenance. ago10 mutants fail to form an embryonic shoot meristem with incomplete penetrance, while they fail to restrict to the size of the postembryonic shoot meristem. ${ }^{102}$ During the process of embryonic shoot meristem initiation, AGO10 acts non-cell autonomously and may potentiate WUS signals to the overlying stem cells. ${ }^{103}$ The postembryonic role for AGO10 is less well understood and the source of conflicting interpretations. One source of confusion is that ago10 mutants appear to increase miR165/166 activity. Normally, if AGO10 acts with miR165/166 to target-specific mRNAs for repression, then removing AGO10 by mutation would tend to impede miR165/166 function. How does AGO10 carry out this nonintuitive role for repressing miRNA activity? A study by Chen et al. concluded that AGO10 directly or indirectly represses miR165/166 transcription, consistent with a prior analysis. ${ }^{100,104}$ However, a separate study from Zhang et al. concluded that AGO10 holds the processed miR165/166 in a nonfunctional complex away from AGO1. ${ }^{105}$

\section{CYTOKININ SIGNALING}

Phytohormones have been known to regulate a variety of plant growth and developmental processes. Cytokinins are one of class of phytohormones regulating proliferation, differentiation of plant cells, tissue culture regeneration, leaf senescence, and more. Cytokinin biosynthesis, distribution, degradation, and perception are closely associated with SAM formation and maintenance. ${ }^{5,11,78,106}$

The KNOX1 class of Arabidopsis transcription factors (STM, KNAT2, and BP) activates cytokinin signaling by the induction of cytokinin isopentenyl transferase (AtIPT7), the enzyme catalyzing the first step of cytokinin biosynthesis. ${ }^{5,107-109}$ LONELY GUY (LOG), which was first identified in rice (Oryza sativa), encodes an enzyme with a phosphoribohydrolase activity that converts inactive biosynthetic cytokinin to its active form. Loss-of-function phenotypes in rice are characterized by a mild reduction in the size of the vegetative meristem, a dramatic reduction of inflorescence meristem activity, and premature termination of flower meristems. ${ }^{110}$ In rice, $L O G$ is expressed at the tip of the first two or three layers of shoot meristem and is not expressed in the OC or differentiating regions, suggesting this $L O G$ expressionregion may have a role to define the maintenance of shoot meristem. $5,11,110$ Subsequently, in Arabidopsis nine rice homolog $L O G$ family members have been identified. Among them, seven LOG proteins (LOG1 to LOG5, LOG7, and LOG8) have variable phosphoribohydrolase activities. ${ }^{111}$ Multiple LOG mutants (up to septuple) indicated that LOGs have overlapping and differentiated functions. ${ }^{111}$ LOG4 and LOG7 are the only two LOG members expressed in the SAM proper. ${ }^{58,112}$ LOG4 is expressed in the L1 cell layer of SAM and floral meristem. The apically produced cytokinin along with CLV signaling is suggested to together form a positional cue for WUS expression in the stem cell niche. ${ }^{112}$ LOG7 has been shown that it has important role in maintaining shoot meristem and root growth. ${ }^{113}$

Cytokinin is perceived by the HISTIDINE KINASE (AHK) receptors and the signal is transmitted to the Arabidopsis Response Regulator (ARR) transcription factors ARR-A and ARR-B. ${ }^{59,114}$ While ARR-B isoforms activate cytokinin signaling, ARRA isoforms downregulate cytokinin signaling. ARR-A class genes appear to act to limit meristem size. ${ }^{59,115}$ In addition, WUS directly represses the transcription of four ARR-As (ARR5, ARR6, ARR7, ARR15), thus enhancing cytokinin signaling. ${ }^{59}$ When ARR7 and ARR15 transcript were silenced via microRNAs, WUS expression and shoot meristem size were mildly increased. ${ }^{115}$ However, the observed reduction of WUS expression in the ARR-A class septuple mutant (arr3 arr 4 arr 5 arr6 arr 7 arr 8 arr 9 ) might indicate a positive role of other ARR-As on WUS. ${ }^{59}$ Furthermore, cytokinin suppresses the expression of CLV1, further complicating the role of cytokinins in meristem function. ${ }^{116,117}$ Thus it appears that cytokinin regulates WUS expression in a CLVdependent and CLV-independent fashion. ${ }^{116,117}$

Cytokinin oxidase/dehydrogenases (CKX) irreversibly catalyzes cytokinin degradation. ${ }^{108}$ Arabidopsis has seven CKX members and each gene has a different pattern of expression during plant development. ${ }^{118}$ The WUS expression domain is expanded in the inflorescence meristem in $c k \times 3 c k \times 5$ mutants. ${ }^{119}$

In addition, STIMPY (STIP), which encodes a WUS-related homeodomain transcription factor also known as WOX9, acts with cytokinin signaling to promote continued proliferation of cells within 
the meristem..$^{5,120,121}$ The loss-of-function stip has reduced number of stem cells compared to those of wild-type after germination. While the wildtype seedling gradually forms a dome-shaped shoot meristem, stip has flat and differentiated shoot meristem and resembles wus mutant phenotype. This stip mutant phenotype can be fully rescued by exogenous sugar application. The sugar-containing medium can induce the $C y c D$ expression, leading to increased cell division. This result shows that STIP acts by maintaining cell division and preventing differentiation in the shoot meristem. ${ }^{121}$ In addition, STIP mediates cytokinin signaling during vegetative development of Arabidopsis. STIP expression in the meristem is induced by cytokinin. The cytokinin triple-receptor mutant (abk2-2 abk3-3 cre1-12) and ARR-B triple mutant (arr1-3 arr10-5 arr12-1) have significantly lower levels of STIP expression. When higher concentrations of exogenously cytokinin, which normally results in growth inhibition, is applied to wild-type and stip seedlings, the stip are less sensitive. In addition, expression of ARR5 (a type A ARR) is reduced in stip mutants and overexpressed STIP partially rescues shoot meristem defects in the cytokinin sensing mutants, indicating STIP works closely with cytokinin signaling. ${ }^{120}$

\section{CHROMATIN REMODELING COMPLEXES IMPACT WUS AND STM EXPRESSION}

Despite the growing understanding of specific aspects of meristem function in general and WUS function in particular, a comprehensive understanding of shoot meristem control and stem cell function is lacking. In the case of WUS expression, the nature of transcriptional control is poorly understood. Because of the intimate and functional relationships between chromatin organization and transcription, one might expect a critical contribution from chromatin regulatory factors in establishing, maintaining, and repressing WUS transcription. Indeed, emerging evidence implicate chromatin remodeling factors, such as chromatin assembly, ATP-dependent chromatin remodeling, and histone modifications have important roles in regulating the transcription of WUS and the equally important $S T M .^{122}$

The FASCIATA1 (FAS1) and FASCIATA2 (FAS2) genes, which encode subunits of chromatin assembly factor- 1 , are required to maintain the organization of shoot and root meristems. fas 1 and fas 2 mutants display fasciated stems because of the shoot meristems become enlarged and disorganized. ${ }^{123}$ In fas 1 and fas 2 mutants, WUS expression is not maintained in the OC, but exhibits variable lateral and apical expansion, indicating these chromatin factors are required for stable, OC-limited expression of WUS. $5,17,122,123$

BRUSHY1 (BRU1) also known as MGOUN3 (MGO3) and TONSOK (TSK) has a function ensuring chromatin reconstitution during DNA replication or repair. bru1 mutants display distorted WUS expression and altered shoot meristem development similar to fas 1 and fas 2 mutants. ${ }^{124}$ However, bru 1 fas double mutants show overlapping and nonoverlapping function on the stability of epigenetic states and the corresponding proteins do not interact in vitro. ${ }^{124}$ $B R U 1$ encodes a novel nuclear protein with two types of protein-protein interaction domains. ${ }^{5,17,122,124-126}$

SPLAYED (SYD), which encodes a SNF2 chromatin-remodeling ATPase, is recruited to the WUS cis elements and controls transcriptional levels of WUS. In syd mutants, WUS expression and meristem size are reduced. ${ }^{5,17,122,127}$ BRCA1-associated RING domain1 (BARD1) protein represses WUS expression by inhibiting SYD. BARD1 encodes a protein containing two tandem BRCA1 C-terminal (BRCT) domains and a RING domain. Loss-of-function mutations in BARD1 result in ectopic expression of WUS throughout the meristem, while over-expression of BARD1 leads to a wus-like phenotype. The BARD1 protein directly binds upstream of the WUS promoter. ${ }^{5,17,122,128}$

The polycomb group $(\mathrm{PcG})$ is important chromatin regulatory complex that silences gene expression by binding specific regions of DNA and inducing posttranslational modifications of histones. ${ }^{129,130} \mathrm{PcG}$ was originally identified in Drosophila and subsequently found in other plants and animals. PcG proteins assemble into at least two complexes called Polycomb Repressive Complex1 (PRC1) and PRC2. PRC2 catalyzes H3K27 methylation and trimethylated H3K27 induces binding of Polycomb (PC), which is a central component of PRC1. PRC1 leads to stable repression by catalyzing monoubiquitination of histone $\mathrm{H} 2 \mathrm{~A}$ via its RING-domain subunits. ${ }^{122,131,132}$ The four core components of PRC2 in animals are E(z), ESC, Su(z)12, and p55. Twelve homologs of these four components are conserved in Arabidopsis. Among different possible PRC2 complexes, CURLY LEAF/SWINGER (CLF/SWN), EMBRYONIC FLOWER2 (EMF2)/VERNALIZATION2 (VRN2), FERTILIZATION INDEPENDENT ENDOSPERM (FIE), and MSI1 play important roles in different stages of the Arabidopsis life cycle. $^{122,133-135}$ 
CLF and the closely related SWN encode histone methyltransferases. ${ }^{6,113}$ CLF binds to the STM cis elements and together with SWN redundantly represses STM expression. ${ }^{5,122,136}$ clf swn double mutants lead to elevated STM expression and a reduction in H3K27me3 at the STM locus. ${ }^{136}$ Derepression of $S T M$ is also observed in mutants of LIKE-HETEROCHROMATIN PROTEIN1 (LHP1) and Atring1a/Atring1b mutants as well. ${ }^{137-140}$ LHP1 encodes a protein similar to heterochromatin regulators metazoans and Schizosaccharomyces pombe. LHP1 may play the role in plants that Polycomb plays in animals, which recognizes $\mathrm{H} 3 \mathrm{~K} 27 \mathrm{me} 3$ and recruits the PRC1-like complex. AtRING1a and AtRING1b are similar to the animal PRC1 core component RING1. ${ }^{140}$

INCURVATA2 (ICU2), which encodes the catalytic subunits of DNA polymerase, also restricts the WUS expression level. In icu2 mutants, WUS expression is upregulated. ${ }^{5,122,141}$ Interestingly, ICU2 interacts with both CLF and LHP1, suggesting a link between multiple DNA replication and chromatin remodeling complexes in controlling the expression critical factors in meristem maintenance. ${ }^{141}$ Another putative DNA-related factor, MGOUN1, which encodes a putative type IB DNA topoisomerase, exhibits synergistic mutant interactions with chromatin remodeling factors SYD, CLF, and LHP1. ${ }^{142}$

\section{CONCLUSIONS}

The large and rapidly growing list of genes with roles in meristem maintenance hints at the tremendous complexity of the process of maintaining active stem cells. In hindsight, this should be readily apparent from the critical importance of shoot meristem for plant growth and architecture and the requirement that these structures adapt to rapidly changing physiological and environmental conditions. Examining individual pathways in isolation is a necessary experimental technique that has taught us much about some of the key processes in meristem maintenance, but we should remain cognizant that each pathway acts as part of a complex web of interacting affects. One only need consider the dizzying array of factors shown to affect WUS transcription to appreciate the underlying complexity.

Considering the directions of future studies, it becomes apparent that despite the rapid progress made in dissecting the pathways controlling shoot meristem maintenance, fundamental aspects of meristem function are completely unknown. What makes a cell in the center of the meristem a stem cell? Specifically, what set of transcription factors, chromatin status, and/or protein activities define a cell as a stem cell? Is it as simple as WUS protein moving into these cells or is WUS just the first step in a long pathway? Either way, what are the key WUS targets that make the stem cells different from every other differentiated cell in the plant? What is the primary effect of CLV signaling? Does it control WUS transcription directly or indirectly? What are the factors downstream of the plasma-membrane localized components? What is the overall role of chromatin remodeling in maintaining stem cells and governing the switch to differentiation?

\section{REFERENCES}

1. Lyndon RF. Control of organogenesis at the shoot apex. New Phytol 1994, 128:1-18.

2. Lyndon RF. The Shoot Apical Meristem: Its Growth and Development. Cambridge, Cambridge University Press; 1998.

3. Medford JI, Behringer FJ, Callos JD, Feldmann KA. Normal and abnormal development in the Arabidopsis vegetative shoot apex. Plant Cell 1992, 4:631-643.

4. Steeves TA, Sussex IM. Patterns in Plant Development. 2nd ed. New York: Cambridge University Press; 1989.

5. Ha CM, Jun JH, Fletcher JC. Shoot apical meristem form and function. Curr Top Dev Biol 2010, 91:103-140.

6. Kerstetter RA, Hake S. Shoot meristem formation in vegetative development. The Plant Cell 1997, 9:1001-1010.

7. Jürgens G, Mayer U, Busch M, Lukowitz W, Laux T. Pattern formation in the Arabidopsis embryo: a genetic perspective. Phil Trans R Soc Lond B Biol Sci 1995, 350:19-25.

8. Jürgens G. Apical-basal pattern formation in Arabidopsis embryogenesis. Embo J 2001, 20: 3609-3616.

9. Laux T, Wurschum T, Breuninger H. Genetic regulation of embryonic pattern formation. Plant Cell 2004, 16(suppl):S190-S202.

10. Long JA, Barton MK. The development of apical embryonic pattern in Arabidopsis. Development 1998, 125:3027-3035. 
11. Barton MK. Twenty years on: the inner workings of the shoot apical meristem, a developmental dynamo. Developmental Biology 2010, 341:95-113.

12. Clark SE. Cell signalling at the shoot meristem. Nat Rev Mol Cell Biol 2001, 2:276-284.

13. Clark SE, Jacobsen SE, Levin JZ, Meyerowitz EM. The CLAVATA and SHOOT MERISTEMLESS loci competitively regulate meristem activity in Arabidopsis. Development 1996, 122:1567-1575.

14. Laux T, Mayer KF, Berger J, Jurgens G. The WUSCHEL gene is required for shoot and floral meristem integrity in Arabidopsis. Development 1996, 122:87-96.

15. Carles CC, Fletcher JC. Shoot apical meristem maintenance: the art of a dynamic balance. Trends Plant Sci 2003, 8:394-401.

16. Clark SE. Organ formation at the vegetative shoot meristem. Plant Cell 1997, 9:1067-1076.

17. Dodsworth S. A diverse and intricate signaling network regulates stem cell fate in the shoot apical meristem. Dev Biol 2009, 336:1-9.

18. Furner IJ, Pumfrey JE. Cell fate in the shoot apical meristem of Arabidopsis thaliana. Development 1992, 115:755-764.

19. Irish VF, Sussex IM. A fate map of the Arabidopsis embryonic shoot apical meristem. Development 1992, 115:745-753.

20. Stewart RN, Blakeslee AF, Avery AG. Demonstration of the three germ layers in the shoot apex of Datura by means of induced polyploidy periclinal chimaeras. Am J Bot 1940, 27:875-905.

21. Stewart RN, Dermen H. Flexibility in ontogeny as shown by the contribution of the shoot apical layers to leaves of periclinal chimeras. Am J Bot 1975 62:935-947.

22. Mayer KF, Schoof H, Haecker A, Lenhard M, Jurgens G, Laux T. Role of WUSCHEL in regulating stem cell fate in the Arabidopsis shoot meristem. Cell 1998, 95:805-815.

23. Schoof H, Lenhard M, Haecker A, Mayer KF, Jurgens G, Laux T. The stem cell population of Arabidopsis shoot meristems in maintained by a regulatory loop between the CLAVATA and WUSCHEL genes. Cell 2000, 100:635-644.

24. Smyth DR, Bowman JL, Meyerowitz EM. Early flower development in Arabidopsis. Plant Cell 1990, 2:755-767.

25. Clark SE, Running MP, Meyerowitz EM. CLAVATA1, a regulator of meristem and flower development in Arabidopsis. Development 1993, 119:397-418.

26. Clark SE, Running MP, Meyerowitz EM. CLAVATA3 is a specific regulator of shoot and floral meristem development affecting the same processes as CLAVATA1. Development 1995, 121:2057-2067.
27. Kayes JM, Clark SE. CLAVATA2, a regulator of meristem and organ development in Arabidopsis. Development 1998, 125:3843-3851.

28. Song SK, Lee MM, Clark SE. POL and PLL1 phosphatases are CLAVATA1 signaling intermediates required for Arabidopsis shoot and floral stem cells. Development 2006, 133:4691-4698.

29. Yadav RK, Perales M, Gruel J, Girke T, Jonsson H, Reddy GV. WUSCHEL protein movement mediates stem cell homeostasis in the Arabidopsis shoot apex. Genes Dev 2011, 25:2025-2030.

30. Brand U, Fletcher JC, Hobe M, Meyerowitz EM, Simon R. Dependence of stem cell fate in Arabidopsis on a feedback loop regulated by CLV3 activity. Science 2000, 289: 617-619.

31. Clark SE, Williams RW, Meyerowitz EM. The CLAVATA1 gene encodes a putative receptor kinase that controls shoot and floral meristem size in Arabidopsis. Cell 1997, 89:575-585.

32. DeYoung BJ, Bickle KL, Schrage KJ, Muskett P, Patel K, Clark SE. The CLAVATA1-related BAM1, BAM2 and BAM3 receptor kinase-like proteins are required for meristem function in Arabidopsis. Plant J 2006, 45:1-16.

33. Fletcher JC, Brand U, Running MP, Simon R, Meyerowitz EM. Signaling of cell fate decisions by CLAVATA3 in Arabidopsis shoot meristems. Science 1999, 283:1911-1914.

34. Jeong S, Trotochaud AE, Clark SE. The Arabidopsis CLAVATA2 gene encodes a receptor-like protein required for the stability of the CLAVATA1 receptorlike kinase. Plant Cell 1999, 11:1925-1934.

35. Muller R, Bleckmann A, Simon R. The receptor kinase CORYNE of Arabidopsis transmits the stem cell-limiting signal CLAVATA3 independently of CLAVATA1. Plant Cell 2008, 20:934-946.

36. Nimchuk ZL, Tarr PT, Meyerowitz EM. An evolutionarily conserved pseudokinase mediates stem cell production in plants. Plant Cell 2011, 23:851-854.

37. Song SK, Clark SE. POL and related phosphatases are dosage-sensitive regulators of meristem and organ development in Arabidopsis. Dev Biol 2005, 285:272-284.

38. Yu LP, Miller AK, Clark SE. POLTERGEIST encodes a protein phosphatase $2 \mathrm{C}$ that regulates CLAVATA pathways controlling stem cell identity at Arabidopsis shoot and flower meristems. Curr Biol 2003, 13:179-188.

39. Reddy GV, Meyerowitz EM. Stem-cell homeostasis and growth dynamics can be uncoupled in the Arabidopsis shoot apex. Science 2005, 310:663-667.

40. Cock JM, McCormick S. A large family of genes that share homology with CLAVATA3. Plant Physiol 2001, 126:939-942. 
41. DeYoung BJ, Clark SE. Signaling through the CLAVATA1 receptor complex. Plant Mol Biol 2001, 46:505-513.

42. Oelkers K, Goffard N, Weiller GF, Gresshoff PM, Mathesius U, Frickey T. Bioinformatic analysis of the CLE signaling peptide family. BMC Plant Biol 2008, $8: 1$.

43. Kondo T, Sawa S, Kinoshita A, Mizuno S, Kakimoto T, Fukuda H, Sakagami Y. A plant peptide encoded by CLV3 identified by in situ MALDI-TOF MS analysis. Science 2006, 313:845-848.

44. Kondo T, Nakamura T, Yokomine K, Sakagami Y. Dual assay for MCLV3 activity reveals structureactivity relationship of CLE peptides. Biochem Biophys Res Commun 2008, 377:312-316.

45. Ni J, Clark SE. Evidence for functional conservation, sufficiency, and proteolytic processing of the CLAVATA3 CLE domain. Plant Physiol 2006, 140:726-733.

46. Ni J, Guo Y, Jin H, Hartsell J, Clark SE. Characterization of a CLE processing activity Plant Mol Biol 2011, $75: 67-75$

47. Ohyama K, Shinohara H, Ogawa-Ohnishi M, Matsubayashi Y. A glycopeptide regulating stem cell fate in Arabidopsis thaliana. Nat Chem Biol 2009, 5:578-580.

48. Lenhard M, Laux T. Stem cell homeostasis in the Arabidopsis shoot meristem is regulated by intercellular movement of CLAVATA3 and its sequestration by CLAVATA1. Development 2003, 130:3163-3173.

49. Nimchuk ZL, Tarr PT, Ohno C, Qu X, Meyerowitz EM. Plant stem cell signaling involves liganddependent trafficking of the CLAVATA1 receptor kinase. Curr Biol 2011, 21:345-352.

50. Rojo E, Sharma VK, Kovaleva V, Raikhel NV, Fletcher JC. CLV3 is localized to the extracellular space, where it activates the Arabidopsis CLAVATA stem cell signaling pathway. Plant Cell 2002, 14:969-977.

51. Bleckmann A, Weidtkamp-Peters S, Seidel CA, Simon R. Stem cell signaling in Arabidopsis requires CRN to localize CLV2 to the plasma membrane. Plant Physiol 2010, 152:166-176.

52. Guo Y, Han L, Hymes M, Denver R, Clark SE. CLAVATA2 forms a distinct CLE-binding receptor complex regulating Arabidopsis stem cell specification. Plant J 2010, 63:899-900.

53. Ogawa M, Shinohara H, Sakagami Y, Matsubayashi Y. Arabidopsis CLV3 peptide directly binds CLV1 ectodomain. Science 2008, 319:294.

54. Kinoshita A, Betsuyaku S, Osakabe Y, Mizuno S, Nagawa S, Stahl Y, Simon R, Yamaguchi-Shinozaki K, Fukuda H, Sawa S. RPK2 is an essential receptor-like kinase that transmits the CLV3 signal in Arabidopsis. Development 2010, 137:3911-3920.

55. Zhu Y, Wang Y, Li R, Song X, Wang Q, Huang S, Jin JB, Liu CM, Lin J. Analysis of interactions among the CLAVATA3 receptors reveals a direct interaction between CLAVATA2 and CORYNE in Arabidopsis. Plant J 2010, 61:223-233.

56. Song SK, Hofhuis H, Lee MM, Clark SE. Key divisions in the early Arabidopsis embryo require POL and PLL1 phosphatases to establish the root stem cell organizer and vascular axis. Dev Cell 2008, 15:98-109.

57. Gagne JM, Clark SE. The Arabidopsis stem sell factor POLTERGEIST is membrane localized and phospholipid stimulated. Plant Cell 2010, 22:729-743.

58. Yadav RK, Girke T, Pasala S, Xie M, Reddy GV. Gene expression map of the Arabidopsis shoot apical meristem stem cell niche. Proc Natl Acad Sci USA 2009, 106:4941-4946.

59. Leibfried A, To JP, Busch W, Stehling S, Kehle A, Demar M, Kieber JJ, Lohmann JU. WUSCHEL controls meristem function by direct regulation of cytokinin-inducible response regulators. Nature 2005, 438:1172-1175.

60. Busch W, Miotk A, Ariel FD, Zhao Z, Forner J, Daum G, Suzaki T, Schuster C, Schultheiss SJ, Leibfried A, et al. Transcriptional control of a plant stem cell niche. Dev Cell 2010, 18:849-861.

61. Yadav RK, Tavakkoli M, Reddy GV. WUSCHEL mediates stem cell homeostasis by regulating stem cell number and patterns of cell division and differentiation of stem cell progenitors. Development 2010, 137:3581-3589.

62. Reddy GV, Heisler MG, Ehrhardt DW, Meyerowitz EM. Real-time lineage analysis reveals oriented cell divisions associated with morphogenesis at the shoot apex of Arabidopsis thaliana. Development 2004, 131:4225-4237.

63. Muller R, Borghi L, Kwiatkowska D, Laufs P, Simon R. Dynamic and compensatory responses of Arabidopsis shoot and floral meristems to CLV3 signaling. Plant Cell 2006, 18:1188-1198.

64. Barton MK, Poethig RS. Formation of the shoot apical meristem in Arabidopsis thaliana: an analysis of development in the wild type and in the shoot meristemless mutant Development 1993, 119:823-831.

65. Endrizzi K, Moussian B, Haecker A, Levin JZ, Laux T. The SHOOT MERISTEMLESS gene is required for maintenance of undifferentiated cells in Arabidopsis shoot and floral meristems and acts at a different regulatory level than the meristem genes WUSCHEL and ZWILLE. Plant J 1996, 10:967-979.

66. Gallois JL, Woodward C, Reddy GV, Sablowski R. Combined SHOOT MERISTEMLESS and WUSCHEL trigger ectopic organogenesis in Arabidopsis. Development 2002, 129:3207-3217.

67. Lenhard M, Jurgens G, Laux T. The WUSCHEL and SHOOTMERISTEMLESS genes fulfil complementary roles in Arabidopsis shoot meristem regulation. Devel opment 2002, 129:3195-3206. 
68. Long JA, Moan EI, Medford JI, Barton MK. A member of the KNOTTED class of homeodomain proteins encoded by the STM gene of Arabidopsis. Nature 1996, 379:66-69.

69. Byrne ME, Barley R, Curtis M, Arroyo JM, Dunham M, Hudson A, Martienssen RA. Asymmetric leaves1 mediates leaf patterning and stem cell function in Arabidopsis. Nature 2000, 408:967-971.

70. Byrne ME, Simorowski J, Martienssen RA. ASYMMETRIC LEAVES1 reveals knox gene redundancy in Arabidopsis. Development 2002, 129:1957-1965.

71. Iwakawa H, Ueno Y, Semiarti E, Onouchi H, Kojima S, Tsukaya H, Hasebe M, Soma T, Ikezaki M, Machida C, et al. The ASYMMETRIC LEAVES2 gene of Arabidopsis thaliana, required for formation of a symmetric flat leaf lamina, encodes a member of a novel family of proteins characterized by cysteine repeats and a leucine zipper. Plant Cell Physiol 2002, 43:467-478.

72. Ori N, Eshed Y, Chuck G, Bowman JL, Hake S. Mechanisms that control knox gene expression in the Arabidopsis shoot. Development 2000, 127:5523-5532.

73. Semiarti E, Ueno Y, Tsukaya H, Iwakawa, H, Machida C, Machida Y. The ASYMMETRIC LEAVES2 gene of Arabidopsis thaliana regulates formation of a symmetric lamina, establishment of venation and repression of meristem-related homeobox genes in leaves. Development 2001, 128:1771-1783.

74. Xu L, Xu Y, Dong A, Sun Y, Pi L, Xu Y, Huang H. Novel as1 and as2 defects in leaf adaxial-abaxial polarity reveal the requirement for ASYMMETRIC LEAVES1 and 2 and ERECTA functions in specifying leaf adaxial identity. Development 2003, 130:4097-4107.

75. Scofield S, Murray JA. KNOX gene function in plant stem cell niches. Plant Mol Biol 2006, 60:929-946.

76. Phelps-Durr TL, Thomas J, Vahab P, Timmermans MC. Maize rough sheath2 and its Arabidopsis orthologue ASYMMETRIC LEAVES1 interact with HIRA, a predicted histone chaperone, to maintain knox gene silencing and determinacy during organogenesis. Plant Cell 2005, 17:2886-2898.

77. Richards DE, King KE, Ait-Ali T, Harberd NP. How gibberellin regulates plant growth and development: a molecular genetic analysis of gibberellin signaling. Annu Rev Plant Physiol Plant Mol Biol 2001, 52:67-88.

78. Veit B. Hormone mediated regulation of the shoot apical meristem. Plant Mol Biol 2009, 69:397-408.

79. Sakamoto T, Kamiya N, Ueguchi-Tanaka M, Iwahori S, Matsuoka M. KNOX homeodomain protein directly suppresses the expression of a gibberellin biosynthetic gene in the tobacco shoot apical meristem. Genes Dev 2001, 15:581-590.
80. Hay A, Kaur H, Phillips A, Hedden P, Hake S, Tsiantis M. The gibberellin pathway mediates KNOTTED1type homeobox function in plants with different body plans. Curr Biol 2002, 12:1557-1565.

81. Bartel DP. MicroRNAs: genomics, biogenesis, mechanism, and function. Cell 2004, 116:281-297.

82. Kim J, Jung JH, Reyes JL, Kim YS, Kim SY, Chung KS, Kim JA, Lee M, Lee Y, Narry Kim V, et al. microRNAdirected cleavage of ATHB15 mRNA regulates vascular development in Arabidopsis inflorescence stems. Plant J 2005, 42:84-94.

83. Rhoades MW, Reinhart BJ, Lim LP, Burge CB, Bartel B, Bartel DP. Prediction of plant microRNA targets. Cell 2002, 110:513-520.

84. Tang G, Reinhart BJ, Bartel DP, Zamore PD. A biochemical framework for RNA silencing in plants. Genes Dev 2003, 17:49-63.

85. Williams L, Grigg SP, Xie M, Christensen S, Fletcher JC. Regulation of Arabidopsis shoot apical meristem and lateral organ formation by microRNA miR166g and its AtHD-ZIP target genes. Development 2005, 132:3657-3668.

86. Reinhart BJ, Weinstein EG, Rhoades MW, Bartel B, Bartel DP. MicroRNAs in plants. Genes Dev 2002, 16:1616-1626.

87. Ariel FD, Manavella PA, Dezar CA, Chan RL. The true story of the HD-Zip family. Trends Plant Sci 2007, 12:419-426.

88. Prigge MJ, Clark, S. E. Evolution of the class III HD-Zip gene family in land plants. Evol Dev 2006, 8:350-361.

89. Green KA, Prigge MJ, Katzman RB, Clark SE. CORONA, a member of the class III homeodomainleucine zipper gene family in Arabidopsis, regulates stem cell specification and organogenesis. Plant Cell 2005, 17:691-704.

90. McConnell JR, Barton MK. Leaf polarity and meristem formation in Arabidopsis. Development 1998, 125:2935-2942.

91. McConnell JR, Emery J, Eshed Y, Bao N, Bowman J, Barton MK., Role of PHABULOSA and PHAVOLUTA in determinging radial patterning in shoot. Nature 2001, 411:709-713.

92. Otsuga D, DeGuzman B, Prigge MJ, Drews GN, Clark SE. REVOLUTA regulates meristem initiation at lateral positions. Plant J 2001, 25:223-236.

93. Prigge MJ, Otsuga D, Alonso JM, Ecker JR, Drews GN, Clark SE, Class III homeodomain-leucine zipper gene family members have overlapping, antagonistic, and distinct roles in Arabidopsis development. Plant Cell 2005, 17:61-76.

94. Waites R, Selvadurai HR, Oliver IR, Hudson A. The PHANTASTICA gene encodes a MYB transcription factor involved in growth and dorsoventrality of lateral organs in Antirrhinum. Cell 1998, 93:779-789. 
95. Hutvagner G, Simard MJ. Argonaute proteins: key players in RNA silencing. Nat Rev Mol Cell Biol 2008, 9:22-32.

96. Vaucheret H. Plant ARGONAUTES. Trends Plant Sci 2008, 13:350-358.

97. Tolia NH, Joshua-Tor L. Slicer and the argonautes. Nat Chem Biol 2007, 3:36-43.

98. Bohmert K, Camus I, Bellini C, Bouchez D, Caboche $\mathrm{M}$, Benning $\mathrm{C}$. AGO1 defines a novel locus of Arabidopsis controlling leaf development. Embo J 1998, 17:170-180.

99. Kidner CA, Martienssen RA. The role of ARGONAUTE1 (AGO1) in meristem formation and identity. Dev Biol 2005, 280:504-517.

100. Liu Q, Yao X, Pi L, Wang H, Cui X, Huang H. The ARGONAUTE10 gene modulates shoot apical meristem maintenance and establishment of leaf polarity by repressing miR165/166 in Arabidopsis. Plant J 2009, $58: 27-40$

101. Lynn K, Fernandez A, Aida M, Sedbrook J, Tasaka M, Masson P, Barton MK. The PINHEAD/ZWILLE gene acts pleiotropically in Arabidopsis development and has overlapping functions with the ARGONAUTE1 gene. Development 1999, 126:469-481.

102. Moussian B, Schoof H, Haecker A, Jurgens G, Laux T. Role of the ZWILLE gene in the regulation of central shoot meristem cell fate during Arabidopsis embryogenesis. Embo J 1998, 17:1799-1809.

103. Tucker MR, Hinze A, Tucker EJ, Takada S, Jurgens G, Laux T. Vascular signalling mediated by ZWILLE potentiates WUSCHEL function during shoot meristem stem cell development in the Arabidopsis embryo. Development 2008, 135:2839-2843.

104. Ji L, Liu X, Yan J, Wang W, Yumul RE, Kim YJ, Dinh TT, Liu J, Cui X, Zheng B, et al. ARGONAUTE10 and ARGONAUTE1 regulate the termination of floral stem cells through two microRNAs in Arabidopsis. PLoS Genet 2011, 7:e1001358.

105. Zhu H, Hu F, Wang R, Zhou X, Sze SH, Liou LW, Barefoot A, Dickman M, Zhang X. Arabidopsis Argonaute10 specifically sequesters miR166/165 to regulate shoot apical meristem development. Cell 2011, 145:242-256.

106. Perilli S, Moubayidin L, Sabatini S. The molecular basis of cytokinin function. Curr Opin Plant Biol 2010, 13:21-26.

107. Jasinski S, Piazza P, Craft J, Hay A,Woolley, L, Rieu I, Phillips A, Hedden P, Tsiantis M. KNOX action in Arabidopsis is mediated by coordinate regulation of cytokinin and gibberellin activities. Curr Biol 2005, 15: $1560-1565$.

108. Sakakibara H. Cytokinins: activity, biosynthesis, and translocation. Annu Rev Plant Biol 2006, 57:431-449.

109. Yanai O, Shani E, Dolezal K, Tarkowski P, Sablowski R, Sandberg G, Samach A, Ori N. Arabidopsis KNOXI proteins activate cytokinin biosynthesis. Curr Biol 2005, 15:1566-1571.

110. Kurakawa T, Ueda N, Maekawa M, Kobayashi K, Kojima M, Nagato Y, Sakakibara H, Kyozuka J. Direct control of shoot meristem activity by a cytokinin-activating enzyme. Nature 2007, 445: $652-655$

111. Kuroha T, Tokunaga H, Kojima M, Ueda N, Ishida T, Nagawa S, Fukuda H, Sugimoto K, Sakakibara H. Functional analyses of LONELY GUY cytokininactivating enzymes reveal the importance of the direct activation pathway in Arabidopsis. Plant Cell 2009, $21: 3152-3169$.

112. Chickarmane VS, Gordon SP, Tarr PT, Heisler MG, Meyerowitz EM. Cytokinin signaling as a positional cue for patterning the apical-basal axis of the growing Arabidopsis shoot meristem. Proc Natl Acad Sci USA 2012, 109:4002-4007.

113. Tokunaga H, Kojima M, Kuroha T, Ishida T, Sugimoto K, Kiba T, Sakakibara H. Arabidopsis lonely guy (LOG) multiple mutants reveal a central role of the LOG-dependent pathway in cytokinin activation. Plant J 2012, 69:355-365.

114. Tucker MR, Laux T. Connecting the paths in plant stem cell regulation. Trends Cell Biol 2007, 17:403-410.

115. Zhao Z, Andersen SU, Ljung K, Dolezal K, Miotk A, Schultheiss SJ, Lohmann JU. Hormonal control of the shoot stem-cell niche. Nature 2010, 465:1089-1092.

116. Gordon SP, Chickarmane VS, Ohno C, Meyerowitz EM. Multiple feedback loops through cytokinin signaling control stem cell number within the Arabidopsis shoot meristem. Proc Natl Acad Sci USA 2009, 106:16529-16534.

117. Lindsay DL, Sawhney VK, Bonham-Smith PC. Cytokinin-induced changes in CLAVATA1 and WUSCHEL expression temporally coincide with altered floral development in Arabidopsis. Plant Science 2006, 170:1111-1117.

118. Werner T, Motyka V, Laucou V, Smets R, Van Onckelen $\mathrm{H}$, Schmulling T. Cytokinin-deficient transgenic Arabidopsis plants show multiple developmental alterations indicating opposite functions of cytokinins in the regulation of shoot and root meristem activity. Plant Cell 2003, 15:2532-2550.

119. Bartrina I, Otto E, Strnad M, Werner T, Schmulling T. Cytokinin regulates the activity of reproductive meristems, flower organ size, ovule formation, and thus seed yield in Arabidopsis thaliana. Plant Cell 2011, 23:69-80.

120. Skylar A, Hong F, Chory J, Weigel D, Wu X. STIMPY mediates cytokinin signaling during shoot meristem establishment in Arabidopsis seedlings. Development 2010, 137:541-549. 
121. Wu X, Dabi T, Weigel D. Requirement of homeobox gene STIMPY/WOX9 for Arabidopsis meristem growth and maintenance. Curr Biol 2005, 15:436-440.

122. Shen WH, Xu L. Chromatin remodeling in stem cell maintenance in Arabidopsis thaliana. Mol Plant 2009, 2:600-609.

123. Kaya H, Shibahara KI, Taoka KI, Iwabuchi M, Stillman B, Araki T. FASCIATA genes for chromatin assembly factor-1 in arabidopsis maintain the cellular organization of apical meristems. Cell 2001, 104:131-142.

124. Takeda S, Tadele Z, Hofmann I, Probst AV, Angelis KJ, Kaya H, Araki T, Mengiste T, Mittelsten Scheid O, Shibahara K, et al. BRU1, a novel link between responses to DNA damage and epigenetic gene silencing in Arabidopsis. Genes Dev 2004, 18:782-793.

125. Guyomarc'h S, Vernoux T, Traas J, Zhou DX, Delarue M. MGOUN3, an Arabidopsis gene with tetratricopeptide-repeat-related motifs, regulates meristem cellular organization. J Exp Bot 2004, 55:673-684.

126. Suzuki T, Inagaki S, Nakajima S, Akashi T, Ohto MA, Kobayashi M, Seki M, Shinozaki K, Kato T, Tabata S, et al. A novel Arabidopsis gene TONSOKU is required for proper cell arrangement in root and shoot apical meristems. Plant J 2004, 38:673-684.

127. Kwon CS, Chen C, Wagner D. WUSCHEL is a primary target for transcriptional regulation by SPLAYED in dynamic control of stem cell fate in Arabidopsis. Genes Dev 2005, 19:992-1003.

128. Han P, Li Q, Zhu YX. Mutation of Arabidopsis BARD1 causes meristem defects by failing to confine WUSCHEL expression to the organizing center. Plant Cell 2008, 20:1482-1493.

129. Muller J, Verrijzer P. Biochemical mechanisms of gene regulation by polycomb group protein complexes. Curr Opin Genet Dev 2009, 19:150-158.

130. Schuettengruber B, Chourrout D, Vervoort $M$, Leblanc B, Cavalli G. Genome regulation by polycomb and trithorax proteins. Cell 2007, 128:735-745.

131. Martin C, Zhang Y. The diverse functions of histone lysine methylation. Nat Rev Mol Cell Biol 2005, 6:838-849.

132. Weake VM, Workman JL. Histone ubiquitination: triggering gene activity. Mol Cell 2008, 29:653-663.
133. Hennig L, Derkacheva M. Diversity of Polycomb group complexes in plants: same rules, different players? Trends Genet 2009, 25:414-423.

134. Pien S, Grossniklaus U. Polycomb group and trithorax group proteins in Arabidopsis. Biochim Biophys Acta 2007, 1769:375-382.

135. Schatlowski N, Creasey K, Goodrich J, Schubert D. Keeping plants in shape: polycomb-group genes and histone methylation. Semin Cell Dev Biol 2008, 19:547-53.

136. Schubert D, Primavesi L, Bishopp A, Roberts G, Doonan J, Jenuwein T, Goodrich J. Silencing by plant Polycomb-group genes requires dispersed trimethylation of histone $\mathrm{H} 3$ at lysine 27. Embo J 2006, 25:4638-4649.

137. Gaudin V, Libault M, Pouteau S, Juul T; Zhao G, Lefebvre D, Grandjean O. Mutations in LIKE HETEROCHROMATIN PROTEIN 1 affect flowering time and plant architecture in Arabidopsis. Development 2001, 128:4847-4858.

138. Kotake T, Takada S, Nakahigashi K, Ohto M, Goto K. Arabidopsis TERMINAL FLOWER 2 gene encodes a heterochromatin protein 1 homolog and represses both FLOWERING LOCUS $\mathrm{T}$ to regulate flowering time and several floral homeotic genes. Plant Cell Physiol 2003, 44:555-564.

139. Turck F, RoudierF, Farrona S, Martin-Magniette ML, Guillaume E, Buisine N, Gagnot S, Martienssen RA, Coupland G, Colot V. Arabidopsis TFL2/LHP1 specifically associates with genes marked by trimethylation of histone H3 lysine 27. PLoS Genet 2007, 3:e86.

140. Xu L, Shen WH. Polycomb silencing of KNOX genes confines shoot stem cell niches in Arabidopsis. Curr Biol 2008, 18:1966-1971.

141. Barrero JM, Gonzalez-Bayon R, del Pozo JC, Ponce MR, Micol JL. INCURVATA2 encodes the catalytic subunit of DNA polymerase alpha and interacts with genes involved in chromatin-mediated cellular memory in Arabidopsis thaliana. Plant Cell 2007, 19:2822-2838

142. Graf P, Dolzblasz A, Wurschum T, Lenhard M, Pfreundt U, Laux T. MGOUN1 encodes an Arabidopsis type IB DNA topoisomerase required in stem cell regulation and to maintain developmentally regulated gene silencing. Plant Cell 2010, 22:716-728. 